\title{
Aspirated voiceless stops in elderly speakers from Calabria: a pilot study
}

\author{
Manuela Frontera \\ Phonetics Laboratory, Department of Languages and Education Sciences, University of \\ Calabria, Italy \\ https://doi.org/10.36505/ExLing-2018/09/0008/000341
}

\begin{abstract}
The aim of this preliminary study is to depict a first sketch of VOT realizations of elderly speakers from the province of Catanzaro (central Calabria, southern region of Italy), to be compared in the near future with data belonging to the Italian-Argentinean community. Thus, the present work represents the starting point of a broader research, aimed at exploring possible cases of phonetic attrition in VOT values of Calabrian migrants in Argentina. Focusing on elderly speakers, /p t k/ stop consonant productions will be analysed within different linguistic contexts. Long lag VOT values are expected to be found, especially if compared to those belonging to adolescent speakers of the same province.

Key words: voiceless stops, VOT, Calabrian varieties
\end{abstract}

\section{Introduction}

Post-aspiration of voiceless stop consonants in Calabrian regional variety is a reported feature since the late 60's. The first studies on the case were based on a perceptual approach, by which the phenomenon seemed to intrude upon the main regional provinces in different ways and diverse phonetic contexts (see Rohlfs, 1966; Falcone, 1976; Canepari, 1986). Later on, acoustic studies on the production of geminated $/ \mathrm{p} \mathrm{t} \mathrm{k/}$ consonants across Italy have demonstrated that adult speakers from the city of Catanzaro show the longest VOT values at all (Stevens, Hajek, 2010). Nevertheless, the unique study focused on VOT analysis in other productive phonetic contexts (post-nasal and post-liquid /p t k/), in the same area, has been led on adolescent speakers only, and from a sociophonetic perspective, showing an attitude to "control" aspiration (considered as spy of a stigmatized variety), in favor of a more standardized pronunciation (Nodari, 2015).

Hence, it has been considered appropriate to try to offer a wider and complete view of this feature in the aforementioned area. Thus, a focus on a more conservative age range seems likely to provide a more objective view of the phenomenon. The present study represents, then, a first step into this new investigation.

ExLing 2018: Proceedings of $9^{\text {th }}$ Tutorial and Research Workshop on Experimental Linguistics, 28-30 August, Paris, Frannce 


\section{Methods \\ Participants}

This work reports the case of the first two speakers involved in the ongoing research, a male and a female, aged 70 and 82 and living in the province of Catanzaro. They have spent their whole life in the same country (Settingiano), speaking dialect as a first language and Italian as a L2, which are the only languages they know and speak.

\section{Corpus}

Speakers were recorded using a Scarlett CM25 microphone and a Focusrite Scarlett $2 \mathrm{i} 2$ audio interface via Sony Sound Forge Pro 11, with a sampling frequency of $44.100 \mathrm{~Hz}$ and a 24 bits resolution.

Speech material is elicited through a reading task consisting of 54 isolated words and 12 sentences in Italian language (232 stimuli). The target words all contain voiceless stops $/ \mathrm{p} \mathrm{t} \mathrm{k/} \mathrm{and} \mathrm{subsume} \mathrm{geminate,}$ post-liquid (-lp, -lt, -lk, -rp, -rt, -rk) and post-nasal (-mp, -nt, -nk) contexts, equally alternating point of articulation, stressed/unstressed syllables (pre-tonic and post-tonic position in paroxytones and proparoxytones) and adjacent vowels $(/ \mathrm{i} /, / \mathrm{a} /, / \mathrm{u} /)$, since each of these contexts intrinsically determines higher or lower VOT values.

\section{Analysis}

All productions are labelled and phonetically annotated, following Abramson and Whalen (2017)'s procedure. Measures are automatically extracted in Praat (Boersma \& Weenink, 2018), summing up REL (release) and ASP (aspiration) durations in each target sound (Kang, Whalen, 2017). VOT is measured starting from the first release burst of the stop consonant up to the acoustic periodic onset of the following vowel (Harrington, 2013). Global mean values and standard deviations associated to different consonants and contexts are then calculated.

\section{Results}

The extracted values are compared according to $\mathrm{C}$ place, adjacent vowels, phonetic contexts and stress position in the target word. In the present study, geminate stops will be analysed only within the phrasal context. Further analyses and possible interactions between variables will be taken into account in future investigations.

\section{Consonant place}

In line with what found by Cho \& Ladefoged (1999), the more backward the consonant place of articulation is, the longer lasts its VOT duration: 
$/ \mathrm{k} /$ mean duration in isolated words is of $78 \mathrm{~ms}($ st. dev. $=23)$ against the pick of $87 \mathrm{~ms}(\mathrm{st} . \mathrm{dev} .=26)$ in $/ \mathrm{k} /$ consonants pronounced in phrasal context. The sound /t/ gets a $61 \mathrm{~ms}$ mean VOT in the word list (st. dev. $=20)$ and $54 \mathrm{~ms}(\mathrm{st} . \mathrm{dev} .=19)$ in the sentences, while $/ \mathrm{p} /$ mean duration is equal to $59 \mathrm{~ms}$ (st. dev. $=19$ ) in isolated words, $52 \mathrm{~ms}$ (st. dev. $=22)$ in phrasal context.

Almost all consonants show long realizations, notably higher than those found both in the spontaneous speech of adolescent speakers from the same Calabrian province (Nodari, 2015) and in the word list from adult speakers of Catanzaro (Stevens, Hajek, 2010).

\section{Adjacent vowel}

Mean VOT values show longer durations when the consecutive vowels are /i/ and /u/, in both diaphasic contexts: $76 \mathrm{~ms}$ vs. $66 \mathrm{~ms}$ for /i/ (st. dev. $=29$ and 28), $74 \mathrm{~ms}$ and $70 \mathrm{~ms}$ for $/ \mathrm{u} /$ (st. dev. $=21$ and 27). VOT before /a/ is averagely equal to $59 \mathrm{~ms}$ (st. dev.=21) in the isolated words, $51 \mathrm{~ms}$ (st. dev. $=21)$ in phrasal context. Thus, this data mirrors the trend of stop consonants to reach longer VOT durations if followed by closed or high vowels (Morris, McCrea, Herring, 2008). Even in this case, post-aspiration is greater than the one produced by younger speakers (max. value $=43 \mathrm{~ms}$ ).

\section{Phonetic context}

Among the main contexts of aspiration, the post-lateral position (-1C) seems to intrude upon VOT values slightly more than the post-nasal and post-rhotic ones, above all in isolated words (Table 1). The obtained values almost double the means found in Nodari (2015).

Table 1. Voiceless stop consonants' VOT in different phonetic contexts.

\begin{tabular}{|c|c|c|}
\hline & \multicolumn{2}{|c|}{ VOT MEANS (MS) } \\
\hline CONTEXT & WORD LIST & SENTENCES \\
\hline$-\mathrm{NC} / \mathrm{MC}$ & $67(18)$ & $60(27)$ \\
\hline$-\mathrm{LC}$ & $72(23)$ & $66(24)$ \\
\hline$-\mathrm{RC}$ & $69(20)$ & $65(28)$ \\
\hline $\mathrm{CC}$ & - & $58(27)$ \\
\hline
\end{tabular}

\section{Stress position}

Dealing with the differences between stressed and unstressed syllables, the data from elderly speakers confirms the presence of longer VOT values in post-tonic position, both in paroxytones $(73 \mathrm{~ms}, \mathrm{SD}=28 ; 63 \mathrm{~ms}, \mathrm{SD}=26)$ and proparoxytones $(72 \mathrm{~ms}, \mathrm{SD}=26 ; 67 \mathrm{~ms}, \mathrm{SD}=47)$, with respect to the pre-tonic positions ( $\mathrm{min}$ value $=59 \mathrm{~ms}$ ). 


\section{Conclusions}

The reported results give rise to some noteworthy remarks: firstly, the obtained data matches the trends tested in the previous works on VOT variation, and confirms the effects of post-liquid/post-nasal positions on $/ \mathrm{p} \mathrm{t} \mathrm{k/'s} \mathrm{degrees} \mathrm{of} \mathrm{aspiration.} \mathrm{Second,} \mathrm{most} \mathrm{importantly,} \mathrm{elderly}$ speakers seem to show post-aspiration levels definitely higher with respect to their younger compatriots, in every investigated context. In order to confirm these important preliminary results, data from a greater amount of speakers and further specific analyses will be provided in future investigations.

\section{References}

Abramson, A.S., Whalen D. 2017. Voice Onset Time (VOT) at 50: Theoretical and practical issues in measuring voicing distinctions. Journal of Phonetics 63, 7586.

Boersma, P., Weenink, D. 2018. Praat: doing phonetics by computer [Computer program]. Version 6.0.37, retrieved 11 May 2018 from http://www.praat.org/

Canepari, L. 1986. Italiano standard e pronunce regionali, Padova: CLEUP.

Cho T., Ladefoged P. 1999. Variation and universals in VOT: evidence from 18 languages. Journal of Phonetics 27, 207-229.

Falcone, G. 1976. Calabria, in M. Cortelazzo (Ed.) Profilo dei dialetti italiani, Pisa: Pacini.

Harrington, J. 2013. Acoustic Phonetics. In Hardcastle, W.J., Laver, J., Gibbon, F.E. (Eds.) The Handbook of Phonetic Sciences (2 ${ }^{\text {nd }}$ Ed.), 81-129. Chichester: Blackwell Publishing.

Kang, J., Whalen, D.H. 2017. get_vot. In https://github.com/HaskinsLabs/get_vot.

Morris, R.J., McCrea, C.R., Herring, K.D. 2008. Voice onset time differences between adult males and females. Journal of Phonetics 36, 308-317.

Nodari, R. 2015. Descrizione acustica delle occlusive sorde aspirate: analisi sociofonetica dell'italiano regionale di adolescenti calabresi. In Vayra, M. Avesani, C., Tamburini, F. (Eds.), Il farsi e disfarsi del linguaggio. Acquisizione, mutamento e destrutturazione della struttura sonora del linguaggio, Studi AISV 1. 139-153. Milano: Officinaventuno.

Rohlfs, G. 1966. Grammatica storica della lingua italiana e i suoi dialetti (I). Torino: Einaudi.

Stevens, M., Hajek, J. 2010. Post-aspiration in standard Italian: some first crossregional acoustic evidence. Proc. Interspeech 1557-15. Makuhari, Japan. 